\title{
Excision of Bile Duct
}

National Cancer Institute

\section{Source}

National Cancer Institute. Excision of Bile Duct. NCI Thesaurus. Code C51577.

Surgical removal of part or all of the bile duct. 